\title{
Knowledge about Condoms among Adolescents in Kathmandu Valley
}

\author{
Jha SM', Chaurasia $\mathrm{R}^{2}$, Jha $\mathrm{B}^{3}$
}

${ }^{1}$ Dr. Sagar Mani Jha, MBBS, MD, Dermato-venereologist, Department of Dermatology and Sexually transmitted Disease, Shree Birendra Hospital, Chhauni, ${ }^{2}$ Dr. Ramesh Chaurasia, Senior Resident, Department of Internal Medicine, B.P. Koirala Institute of Health Science, ${ }^{3}$ Dr. Beena Jha, General Practioneer, Kathmandu, Nepal.

Address for correspondence: Dr. Sagar Mani Jha, E-Mail: drsagarmani_jha@hotmail.com

\begin{abstract}
Introduction: The issues of sexual and reproductive health (SRH) remain the leading cause of ill health among adolescents worldwide and are of growing concern in Nepal. The correct knowledge of condoms is integral part of SRH. The present study was carried out to assess and compare the knowledge about condoms among adolescents in the Kathmandu valley of Nepal. Aim: To study, assess and compare the knowledge about condoms among adolescents in the Kathmandu valley of Nepal. Methods: The study was a cross-sectional questionnaire-based survey. The sample was derived through cluster sampling of the secondary schools in the Kathmandu valley. Schools were selected randomly and two hundred and fifty adolescents were taken from each government and non-government high schools. Result: Altogether 500 adolescents were recruited for this study. A total of 298 (53.0\%) participants said that condoms reduced pleasure. Most women don't like to use condoms was agreed by $291(55.6 \%)$ people and it was statistically significant $(p$ value $<0.05)$ when compared between males and females. Using condoms with new partner is a good idea was agreed upon by $448(81.0 \%)$ participants. Women should ask their partners to use condoms was answered by $480(88.1 \%)$ and discussing condom use with prospective partner is easy was agreed by $417(79.0 \%$ ) and both the issues were also statistically significant ( $p$ value $<$ $0.05)$. Conclusion: It was found that the knowledge about condoms was not adequate and the knowledge among male participants was in general better than females.
\end{abstract}

Key words: Adolescents, Condom, Sexual and reproductive Health

\section{Introduction}

T he issues of sexual and reproductive health ( $\mathrm{SRH})$ remain the leading cause of ill health among adolescents worldwide and are of growing concern in Nepal. WHO estimates that 340 million new cases of bacterial sexually transmitted infections, such as chlamydia and gonorrhoea occur annually in people aged 15- 49 years. In addition, millions of cases of viral infection, including HIV occur every year ${ }^{1}$. These figures indicate that the correct and rational knowledge of condoms is integral part of $\mathrm{SRH}$ and all efforts should be made to educate the adolescents about them. Many adolescents lack the power and skill to use contraceptives, especially young women who must negotiate the use of condoms with a male partner. Males generally have more ability to use a condom than females. According to a Cameroon study, males report knowing how to use a condom correctly, how to negotiate condom use, and being willing to buy a condom more often than females. Young adults also lack access to contraceptive services or methods. Many young women are forced to have sex and have no control over contraceptive use. Even if sexually active youth do plan ahead to prevent pregnancy, they still may be vulnerable to sexually transmitted infections if they do not use condoms consistently and correctly. 
Although adolescents' and young adults' knowledge of contraception is increasing, their use lags far behind ${ }^{2}$. Rates of contraceptive use among sexually active male adolescents and young adults have been found to be $56 \%$ in Costa Rica and Rio de Janeiro in $82 \%$ in Mexico City $^{3}$. Various studies show that the most common method used by male adolescents is the use of condoms. An Indian Council of Medical Research (ICMR) study showed that about one-half of the adolescents were not aware of condoms and were confused about the various modes of HIVIAIDS transmission ${ }^{4}$. In Bangladesh and Indonesia, only $5 \%$ and in the Philippines only $9 \%$ of married girls between $15-19$ years of age knew without prompting that condoms prevent HIV. In contrast, $24 \%$ of married girls aged $15-19$ in Nepal and $65 \%$ of married boys know this ${ }^{5}$. In a study conducted in US on average, teenagers reported a high level of perceived condom knowledge; $87 \%$ of teenagers had received pregnancy and AIDS education in school ${ }^{6}$. This study gives a brief overview about the level of knowledge about condoms among adolescents in Kathmandu.

\section{Material and methods}

This study is a cross-sectional questionnairebased survey done in the Kathmandu Valley, Nepal. The sample was derived through cluster sampling of the secondary schools in the Kathmandu valley. Since samples were selected randomly it is presumed that it truly represents the adolescents of Kathmandu valley. A total of 5 schools were selected randomly out of which 3 were government and two were non government schools. Two hundred and fifty adolescents were taken from each government and non-government high schools. A total of 500 adolescents were recruited for this study. Adolescents between 13 to 19 years of age both sexes who were between class 8 and class 12 were included. All students irrespective of caste, creed or ethnicity were included however majority of students were newar, brahmin, chhetri, other janjatis and few were madhesis. Adolescents aged between 10 to 12 years were excluded. Data were collected using self administered structured questionnaire. As the sexual and reproductive health education has been incorporated in the curriculum of high schools of Nepal and there is massive media campaign about condoms in the country, it was expected that the adolescents have enough knowledge about condoms and hence could answer the questionnaire correctly. The questionnaire in English language were translated and standardized in Nepali language with standard method. The questionnaire comprised of 12 questions about condoms and participants were asked to tick or cross mark it, if they thought the answer was correct or incorrect respectively. The questions were short and easy to understand. The instructions for the adolescents were mentioned in the questionnaire. The researcher and assistants who understand the local languages helped in administration of the questionnaire to the adolescents. Several measures were taken to ensure the confidentially. The questionnaire was self administered and participants were asked to drop the completed questionnaire in the sealed box. Informed consent of the individuals was taken and they were explained and allowed to skip the questions if they don't wish to answer any particular question. They were also allowed to discontinue their participation from this study at any point of time if they wished to do so. Data was tabulated and interpreted in terms of percentage in the computer using SPSS version 10.0. To test the significance of association Chi square test was applied.

\section{Results}

Demographic Profile: Altogether 500 adolescents between 13-19 years of age were included. Age of the study subjects ranged from 13-18 years with a mean age of 15.85 years ( $S D \pm 1.66$ ). Out of these participants 311 were males and 189 were females.

\section{Assessment of knowledge about condoms}

Various questions were asked covering different aspects of condoms, 180 (43.3\%) participants said that condoms reduced pleasure. Altogether 310 (68.8\%) said partner should have self control while using condoms. A total of $261(56.7 \%)$ participants correctly answered that condoms can't be used more than once. It was embarrassing to buy condoms in pharmacy and Family Planning Clinics for 433 (90.2\%) and 426 (88.2\%) people respectively. Three hundred and seventeen (66.7\%) people said most women don't like to use condoms where as 420 (94.8\%) people said most men do not like condoms. Using condoms with new partner is a good idea was agreed upon by $303(67.7 \%)$ people. Using condom is not necessary if you know the partner was not agreed by $131(27.4 \%)$ participants. Women should ask their partners to use condoms was agreed by 121 $(26.3 \%)$ and discussing condom use with prospective partner is easy was agreed upon by 218 (45.6\%). Condoms are messy to use was believed by 335 (77.9\%) adolescents (Table 1). 
Table 1: Knowledge about condoms in adolescents

\begin{tabular}{|l|c|c|c|c|c|}
\hline Statements & Number & Agree & (\%) & Disagree & (\%) \\
\hline Condoms reduce pleasure of sex & 416 & 180 & 43.3 & 236 & 56.7 \\
\hline Condoms require partner's self control & 450 & 310 & 68.8 & 140 & 31.2 \\
\hline Condom can be used more than once & 461 & 200 & 43.3 & 261 & 56.7 \\
\hline It is embarrassing to buy condoms in pharmacy & 480 & 433 & 90.2 & 47 & 9.8 \\
\hline It is embarrassing to get condoms from Family Planning Clinic & 483 & 426 & 88.2 & 57 & 11.8 \\
\hline Most women do not like condoms & 475 & 317 & 66.7 & 158 & 33.3 \\
\hline Most men do not like condoms & 443 & 420 & 94.8 & 23 & 5.2 \\
\hline Using condom with new partner is good idea & 447 & 303 & 67.7 & 144 & 32.3 \\
\hline Using condom is not necessary if you know the partner & 479 & 348 & 72.6 & 131 & 27.4 \\
\hline Women should ask their partners to use condoms & 460 & 121 & 26.3 & 339 & 73.7 \\
\hline Discussing condom use with prospective partner is easy & 478 & 218 & 45.6 & 260 & 54.4 \\
\hline Condoms are messy to use & 430 & 335 & 77.9 & 95 & 22.1 \\
\hline
\end{tabular}

\section{Comparision of knowledge about condoms between male and female participants}

Among 311 boys and 189 girls who participated some of the participants skipped certain questions. It was clear from the answers that out of 293 boys, $225(76.8 \%)$ believed that most women do not like condoms where as out of 182 only 92 (50.5\%) girls believed it which was statistically significant $\{p$ value: 0.007, Odds Ratio (OR):0.66, Confidence interval (CI)) $0.48-0.90\}$. Using condom with new partner is a good idea was agreed upon by $220(75.1 \%)$ out of 293 boys and $83(53.9 \%$ ) out of 154 girls, ( $p$ value: 0.04 , OR: 0.72 , Cl: $0.52-1.00)$. Using condom is not necessary if you know the partner, 267 (89.3\%) boys and 81(45\%) girls out of 299 boys and 180 girls thought it to be correct ( $p$ value: $0.000, \mathrm{OR}: 0.50, \mathrm{Cl}: 0.37-0.69$ ). A total of 307 boys and 153 girls expressed their opinion that women should ask their partners to use condoms out of which $57(18.5 \%)$ were boys and $64(41.8 \%)$ were girls ( $p$ value: 0.000 , OR: $2.25, \mathrm{Cl}: 1.47-3.45)$. Discussing condom use with prospective partner was thought to be easy by $166(56.5 \%)$ males and $52(28.3 \%)$ females out of 294 and 184 males and females respectively, ( $p$ value: $0.0001, \mathrm{OR}: 0.50, \mathrm{Cl}: 0.34-0.73$ ). Condoms are messy to use was believed by $270(88.5 \%)$ males and 65 (52\%) females out of 305 males and 125 females ( $p$ value: $0.002, \mathrm{OR}: 0.59, \mathrm{Cl}: 0.41-0.84$ )

\section{Discussion}

Adolescence is a period of rapid growth and development of body, mind, social relationship and so also sexual relationship. Physical growth is accompanied by sexual maturation leading to intimate relationship which, if not guided properly leads to various problems. By promoting sexual literacy, sex education can contribute to psychosocial development and well-being throughout adolescence and adulthood. The absence of sexual literacy can be the source of many health and social hazards, including STDs and unintended pregnancy ${ }^{7}$. Our study investigated the knowledge and awareness about condoms among adolescents in the Kathmandu valley. We selected the private as well as government schools in Kathmandu, Nepal.

The study population altogether comprised of five hundred adolescents, from thirteen to nineteen years of age. The participants comprised of both males and females with a sex ratio of approximately 1.5:1. Thus the problem, knowledge and awareness regarding condoms among the study population are likely to represent the school going adolescents in Kathmandu.

In our study condoms reducing pleasure was agreed upon by $43.3 \%$ and disagreed by $56.7 \%$ of the participants but the difference was not statistically significant between boys and girls. Similar was the case among males and female when it was asked whether a partner should have self control while using condom. Quite a high number of participants thought that condoms can be used more than once; this indicates that much has to be done in the field of reproductive health. Reproductive health education in the school, media campaign and role of parents are few means of educating the adolescents.

It was embarrassing to get condoms from Family Planning Clinic $(88.2 \%)$ or pharmacy $(90.2 \%)$ for the participants. In Nepal where talking about sex is still a taboo, going to a pharmacy and getting a condom is unthinkable by adolescents especially by females. Due to this embarrassment the adolescents don't use contraception and hence SRH problems arise.

The other common reasons youth give in surveys is that they lack information about contraceptives and 
they lack access to contraceptives. Most clinics are not designed in a way that will be inviting young clients. Providers are sometimes reluctant to give contraceptives to young people, especially to those who are unmarried. In some countries, laws or policies prohibit provision of contraceptive methods to unmarried youth. In Zanzibar, unmarried women are denied contraceptives from health professionals, while in Botswana and Senegal, married women are restricted from using contraceptives without the permission of their husbands ${ }^{8}$.

Often, adolescents lack money for SRH services and for contraceptives including condoms. Young people may be afraid of being judged by providers or adult clients, or they may be worried about being discovered by their parents. Even if youth know about contraceptives, such as condoms, they often do not know where to get them or how to use them correctly. Most women (66.7\%) and men $(94.8 \%)$ do not like using condoms can be seen in our study. In various studies young men mention lack of knowledge more than young women. Also, men do not usually see contraception as their responsibility. This could be the reason for men not liking to use condom. It can also be seen in this study that among males $76.8 \%$ and females $50.5 \%$ participants thought that most women do not like condoms and it was statistically significant $p$ value being 0.007 .

Many adolescents lack the power and skill to use contraceptives, especially young women who must negotiate the use of condoms with a male partner. Many young women are forced to have sex and have no control over contraceptive use. There may also be cultural expectations or beliefs that limit the use of contraception

Condoms should be used while having sexual contact with new partner was agreed by $67.7 \%$ of participants and it was found that the issue was statistically significant ( $p$ value:0.04) when compared between males and females. Using condom is not necessary if they knew the partner was agreed by $72.6 \%$ adolescents and it was also statistically significant.

Few married young couples use contraception before the birth of their first child. Among unmarried young a U.S. study found that young people typically delay using contraception until about a year after beginning sexual activity. In surveys in Latin America and in Kenya, unmarried youth say the main reason they did not use contraception was because they did not expect to have sex at that time. Sexual activity tends to be sporadic and unplanned among young adults.
When asked whether women should ask their partners to use condoms, only $26.3 \%$ participants had agreed in this study out of which $57(18.5 \%)$ were boys and $64(41.8 \%)$ were girls ( $p$ value: 0.000$)$. Women who are financially, materially or socially dependent on men may have limited power to exercise control in relationships, such as negotiating the use of condoms during sex. Social expectations about how women should behave can place women in subordinate roles and increase their risk of being sexually assaulted, contracting STIs and having unwanted pregnancies, and also limit their access to SRH services.

One primary component of effective pregnancy and STD prevention programs is teaching teenagers to negotiate sexual activity and contraceptive use with dating partners and, if they engage in sex, to discuss contraception and STDs with a partner before they do so $^{9}$. In a small survey of undergraduate students, females reported discussing contraception with their partners and encouraging their first partners to use contraceptives more often than males ${ }^{10}$. Discussing condom use with prospective partner is easy and condoms are messy to use was agreed upon by $45.6 \%$ and $77.9 \%$ of participants respectively which was also statistically significant. At this stage of life, most young people focus on the present and tend not to plan ahead or anticipate the long-term consequences of their choices. Many unmarried adolscents think of contraception or family planning as something that only married couples do; they do not think of themselves as "planning a family" and they may have difficulty discussing contraception. The sociocultural structure of the Nepalese society prevents adolescents from talking on sexual matters. Taking about condoms and using them properly requires adequate time and place. But in this part of world where indulging in sex before marriage is unacceptable, there is always lack of time and place and there is always fear of getting caught while performing the act which prevents the adolescents from talking and properly using condoms.

\section{Conclusion}

In countries like ours, this study has great relevance today because despite massive campaign by mass media, non-governmental and governmental organizations quite a large population of adolescents are falling prey to STIs and unwanted pregnancies. Knowledge about condoms among adolescents was not adequate among participants. In general, knowledge of boys was better than girls however in certain aspects females had better knowledge about condoms. Further intervention is required to enhance the knowledge about condoms among adolescents which would give them 
better chance to protect themselves from various STIs and unwanted pregnancy.

Acknowledgment: It gives me great pleasure to express my deep sense of gratitude to my highly respectable teachers Prof Sudha Agrawal and Dr. Tapan Kumar Dhali for their excellent and able guidance in performing this study. Similarly I am grateful to Dr. Arun Neopane Editor in Chief of JNPS, for his constant encouragement. I am greatly indebted to all my participants, without whose co-operation, this work would not have been possible.

Limitation of this study: The names and localities of the schools have not been mentioned deliberately since it was requested by the authorities of some of the schools. Even mentioning the name of localities would have breached the secrecy as some of the localities have only one school.

\section{Conflict of interest: None}

\section{Fundings: None}

\section{References}

1. WHO/UNFPA. Top Level Push to Tackle Priorities in Sexual and Reproductive Health. Medical News Today, 22 June 2006.

2. Population Reference Bureau. Adolescent Sexual Activity and Childbearing in Latin America and the Caribbean: Risks and Consequences. Washington DC: Population Reference Bureau, 1992.

3. Lundgren R. Research Protocol to Study Sexual and Reproductive Health of Male Adolescents and Young Adults in Latin America, 2000; 1-100.
4. Gupta S D. Adolescent Reproductive Health in India.Status, Policies, Programs, and Issues Indian Institute of Health Management Research Jaipur, India ,January ; 2003.

5. Demographic and Health Surveys, HIVIAIDS Survey Indicators Database. [Online].2007 [cited 2007 Aug 22]; Available from: URL: http://www. measuredhs.com

6. Ryan S, Franzetta K, Holcombe EMJ. Adolescents' Discussions about Contraception or STDs with Partners before first sex. Perspectives on Sexual and Reproductive Health, 2007, 39(3):149-157.

7. Shtarkshall R A, Santelli J S, Hirschxual J S. Sex Education and Sexual Socialization: Roles for Educators and Parents. Perspectives on Sexual and Reproductive Health 2007; 39 (2).

8. Haile S, Guerny du J, Stloukal L. Provision of reproductive health services in sub-Saharan Africa: lessons, issues, challenges and the overlooked rural majority a review of access to reproductive health services in rural areas. Sustainable Development Department, FAO SD Dimensions; 2000.

9. Kirby D, Laris BA and Rolleri L, Sex and HIV Education Programs for Youth: Their Impact and Important Characteristics, Scotts Valley, CA: ETR Associates; 2006.

10. Poppen PJ, Adolescent contraceptive use and communication: Changes over a decade. Adolescence 1994; 29(115):503-514. 